\title{
Preparation of Titanium Phosphates with Sodium Triphosphate in Hydrothermal Process and Their Powder Properties for Cosmetics
}

\author{
Hiroaki Onoda*, Taisuke Yamaguchi \\ Department of Informatics and Environmental Sciences, Kyoto Prefectural University, Kyoto, Japan \\ Email: *onoda@kpu.ac.jp
}

Received November 24, 2012; revised March 2, 2013; accepted March 18, 2013

\begin{abstract}
As a white pigment, titanium oxide is used for cosmetic application. This oxide is well known to have the photo catalytic activity. Therefore, a certain degree of sebum on the skin is decomposed by the ultraviolet radiation in sunlight. In this work, titanium phosphates were prepared with titanium chloride and sodium triphosphate in hydrothermal process as a novel white pigment. Their chemical composition, powder properties, photo catalytic activity, color phase, and smoothness were studied. The obtained phosphates had little photo catalytic activity. The particle size of phosphate pigments consisted of a normal distribution at $2 \mu \mathrm{m}$ by the hydrothermal treatment for 4 and 8 hours. The slipping resistance of samples became small by the hydrothermal treatment.
\end{abstract}

Keywords: Titanium Phosphates; Condensed Phosphate; Hydrothermal Process; Photo Catalytic Activity; Smoothness

\section{Introduction}

As a white pigment, titanium dioxide is used for cosmetic application [1]. This oxide is well known to have the photo catalytic activity. Therefore, a certain degree of sebum on the skin is decomposed by the ultraviolet radiation in sunlight. To repress this effect, some kinds of the technical process are investigated and used. For example, as one of these techniques, the composite particles with silicon oxide are used [2]. However, these particles are hard materials for human face. The mild materials for human face are required as a white pigment. In addition, there was a report that microfine titanium dioxide would be adsorbed through the skin [3]. The novel white pigment that is not adsorbed is required.

Phosphates have been used for ceramic materials, catalysts, adsorbent, fluorescent materials, dielectric substances, biomaterials, for metal surface treatment, as fertilizer, detergents, food additives, in fuel cells, pigments, and other items [4-8]. It is well known that phosphate materials have high affinity for a living body. Therefore, as a novel white pigment, phosphates have a possibility for the cosmetics.

As a pigment for cosmetics, the particle shape and size distribution are important. Sphere homogenized particle are expected to spread well on the skin. However, too much small particles are not suitable because pigments

"Corresponding author. got into the pores in the skin. The hydrothermal process is generally used to control the powder properties of inorganic phosphate materials [9-11]. The time of the hydrothermal treatment had important factor such as temperature, reactant concentration, and $\mathrm{pH}$ values. In previous work [12], we prepared the titanium phosphate pigment that had no catalytic activity. However, the obtained particles had the wide distribution from $1 \mu \mathrm{m}$ to $300 \mu \mathrm{m}$ in size. Therefore, the purpose in this work is to obtain the homogenized titanium phosphate particles.

Phosphates are transformed to other forms of phosphates by hydrolysis and dehydration reactions at elevated temperatures. These condensed phosphates have the possibility to have novel functional properties. Orthophosphate has been mainly investigated for many applications, on the other hand, condensed phosphates have been little studied.

In this work, titanium phosphates were prepared from titanium chloride and sodium triphosphate solution in hydrothermal process for several hours. Their chemical composition, powder properties, photo catalytic activity, color phases, and smoothness of the obtained precipitates and their thermal products were studied for the cosmetic application.

\section{Experimental}

Sodium triphosphate, $\mathrm{Na}_{5} \mathrm{P}_{3} \mathrm{O}_{10}$, was synthesized by heating the mixture of disodium hydrogen phosphate, 
$\mathrm{Na}_{2} \mathrm{HPO}_{4}$, and sodium dihydrogen phosphate, $\mathrm{NaH}_{2} \mathrm{PO}_{4}$, at $400^{\circ} \mathrm{C}$ for 5 hours. $0.1 \mathrm{~mol} / 1$ of titanium chloride solution was mixed with $0.1 \mathrm{~mol} / \mathrm{l}$ of the sodium triphosphate solution in a molar ratio of Ti/P $=5 / 12$. This ratio of Ti/P was determined from the theoretical chemical composition of $\operatorname{Ti}_{5}\left(\mathrm{P}_{3} \mathrm{O}_{10}\right)_{4}$. The mixed solution was set in the autoclave for $0,2,4,6,8$, and 12 hours at $120^{\circ} \mathrm{C}$ and 100 $\mathrm{kPa}$ (hydrothermal treatment). Then, the precipitates were filtered off, washed with water, and dried.

The chemical composition of these materials was analyzed by XRD. XRD patterns were recorded on a Rigaku Denki RINT 2000 X-Ray diffractometer using monochromated $\mathrm{CuK} \alpha$ radiation. TG and DTA curves of precipitates were measured with a Shimadzu DTG-60H at a heating rate of $10 \mathrm{~K}_{\text {minute }}{ }^{-1}$ in air. Samples were heated at $100^{\circ} \mathrm{C}, 200^{\circ} \mathrm{C}, 400^{\circ} \mathrm{C}, 600^{\circ} \mathrm{C}$ in air conditions. These thermal products were also analyzed by XRD patterns.

The powder properties of the precipitates and their thermal products were estimated from SEM images and particle size distributions. Scanning electron microscopy (SEM) images of titanium phosphates were observed using JGM-5510LV, JEOL Ltd. The particle size distributions of these materials were measured with laser diffraction/scattering particle size distribution HORIBA LA-910.

The cosmetic properties were estimated by the photo catalytic activity, the color phase, and the smoothness. The photo catalytic activity of samples was estimated with the decomposition of methylene blue by $365 \mathrm{~nm}$ radiation $[13,14]$. The color of phosphate pigments was estimated by ultraviolet-visible (UV-Vis) reflectance spectra with a Shimadzu UV2550. The smoothness of particles was measured on an artificial leather with KESSE objective evaluation of surface friction property, KATO Tech Co. Ltd.

\section{Results and Discussion}

\subsection{Chemical Composition of Precipitates}

Figure 1 shows XRD patterns of samples prepared in hydrothermal process for several hours. All samples had XRD peaks of $\mathrm{TiP}_{3} \mathrm{O}_{9}$ in spite of the hydrothermal hours [15]. This chemical composition had a different ratio of $\mathrm{Ti} / \mathrm{P}$ from those prepared under experimental conditions. The chemical composition $\mathrm{P}_{3} \mathrm{O}_{9}^{3-}$ represents a Cyclotriphosphate anion described in a recent report [16]. Cyclo-triphosphate was probably not formed in this condition. As inferred from the regularity in phosphate chemistry, titanium Cyclo-triphosphate was not synthesized by heating [17]. Another fault was that tetravalent titanium cation reduced to trivalent cation. We infer that this compound was a mixture of $\mathrm{TiO}\left(\mathrm{PO}_{3}\right)_{2}$ and $\mathrm{Ti}\left(\mathrm{PO}_{3}\right)_{4}$. The previous work was unable to distinguish between $\mathrm{TiP}_{3} \mathrm{O}_{9}$ and the mixture of $\mathrm{TiO}\left(\mathrm{PO}_{3}\right)_{2}$ and $\mathrm{Ti}\left(\mathrm{PO}_{3}\right)_{4}$ (for

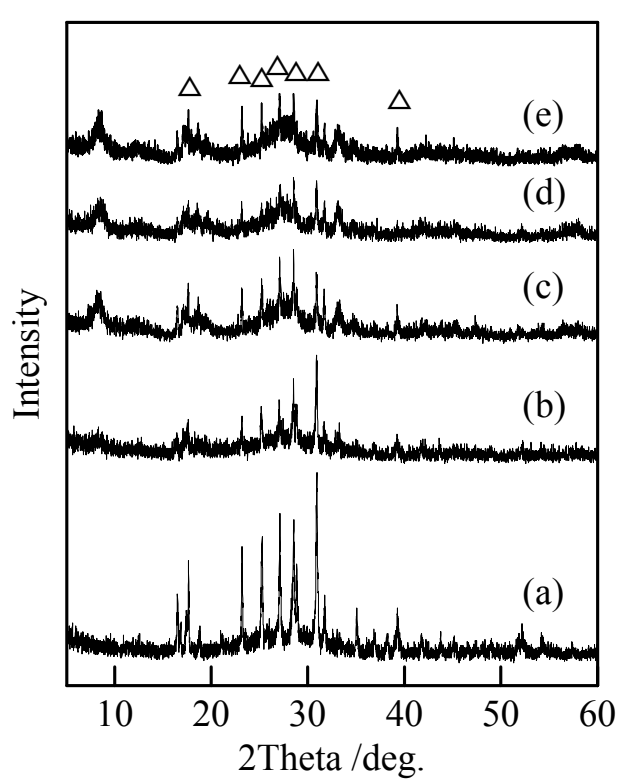

Figure 1. XRD patterns of samples prepared in hydrothermal treatment for various hours, (a) 0 , (b) 2 , (c) 4 , (d) 8 , and (e) 12 hours, $\triangle$; $\mathrm{TiP}_{3} \mathrm{O}_{9}$.

example $\mathrm{Ti}_{2} \mathrm{O}\left(\mathrm{PO}_{3}\right)_{6}$. The peak intensity became weak by the hydrothermal treatment. All samples had a certain degree of amorphous phase. By heating at $600^{\circ} \mathrm{C}$, the peaks of $\mathrm{TiO}_{2}$ appeared in XRD patterns.

Figure 2 shows TG curves of samples prepared in hydrothermal process for several hours. The weight losses at $600^{\circ} \mathrm{C}$ were $14.4 \%, 16.7 \%, 17.9 \%, 20.1 \%$, and $20.2 \%$ in TG curves of samples prepared for $0,2,4,8$, and 12 hours, respectively. With the increase of hydrothermal hours, these weight losses below $600^{\circ} \mathrm{C}$ became larger. Especially, samples prepared for 8 and 12 hours had the step at $230^{\circ} \mathrm{C}$ in $\mathrm{TG}$ curve. By the hydrothermal treatment, titanium phosphates became easy to contain water, hydroxide anion, and so on.

Figure 3 shows DTA curves of samples prepared in hydrothermal process for several hours. The endothermic peaks at $70^{\circ} \mathrm{C}$ and $110^{\circ} \mathrm{C}$ were observed in DTA curves of all samples. These peaks were due to the volatilization of adsorbed and crystalline water. Sample prepared without the hydrothermal treatment had an exothermic peak at $550^{\circ} \mathrm{C}$ and an endothermic peak at $590^{\circ} \mathrm{C}$ in DTA curve. These peaks were considered from the transition of chemical phases. By the hydrothermal treatment, the transition took place in the exothermic reactions at $590^{\circ} \mathrm{C}$ and $680^{\circ} \mathrm{C}$. A small endothermic peak at $270^{\circ} \mathrm{C}$ appeared in DTA curves in samples prepared with the hydrothermal treatment. This peak was due to the volatilization of water from the condensation of hydroxide anions.

\subsection{Powder Properties of Titanium Phosphates}

From the viewpoint of particle shape, spherical particles 


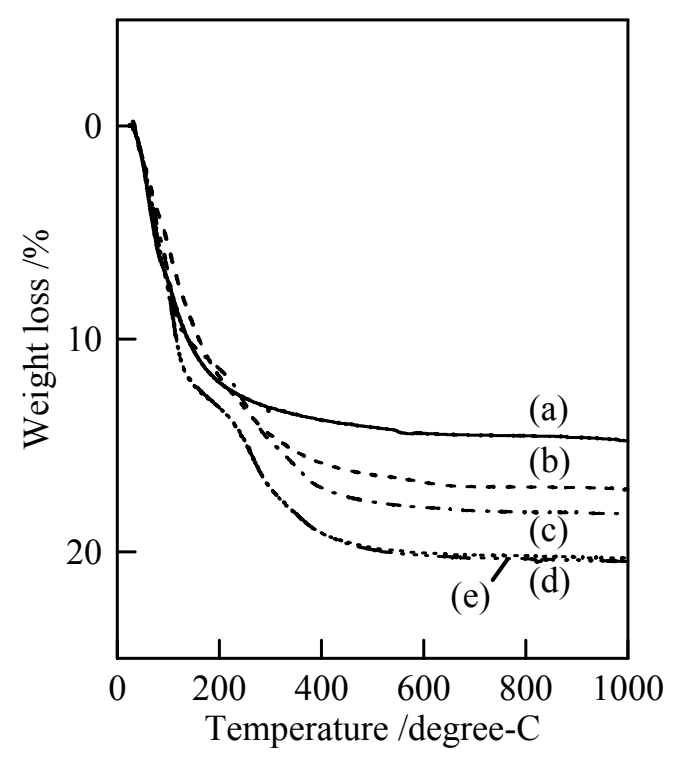

Figure 2. TG curves of samples prepared in hydrothermal treatment for various hours, (a) 0 , (b) 2, (c) 4, (d) 8, and (e) 12 hours.

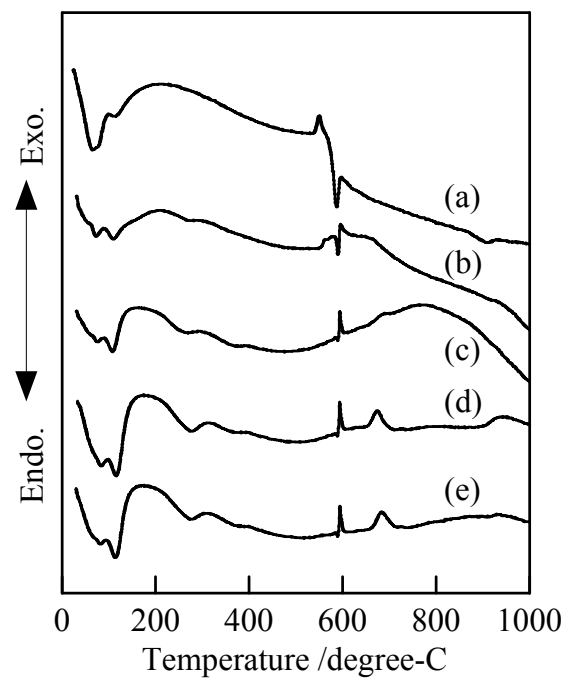

Figure 3. DTA curves of samples prepared in hydrothermal treatment for various hours, (a) 0 , (b) 2 , (c) 4 , (d) 8 , and (e) 12 hours.

are suitable for the cosmetic applications. Figure 4 shows SEM images of samples prepared in hydrothermal process for several hours. All samples had no specified shape in spite of the hydrothermal time. The particle size in SEM images became smaller with the hydrothermal hours.

Figure 5 shows the particle size distribution of samples prepared in hydrothermal process for several hours. The main part of particles was from 0.5 to $400 \mu \mathrm{m}$. The ratios at 3 and $30 \mu \mathrm{m}$ were high in the distribution of sample prepared without the hydrothermal treatment (Figure 5(a)). Sample prepared with the hydrothermal treatment
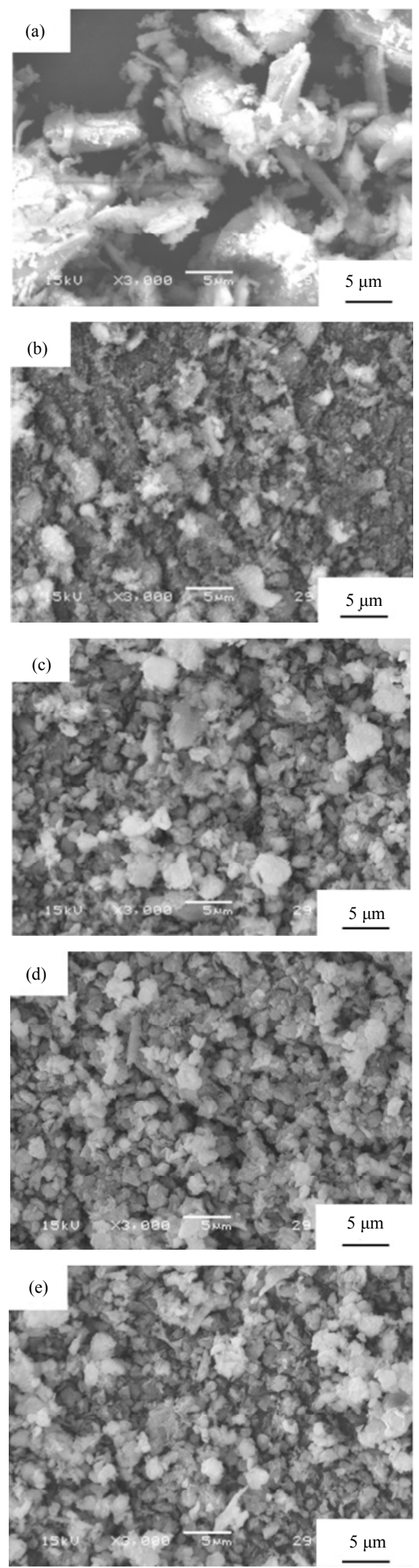

Figure 4. SEM images of samples prepared in hydrothermal treatment for various hours, (a) 0 , (b) 2, (c) 4, (d) 8, and (e) 12 hours. 


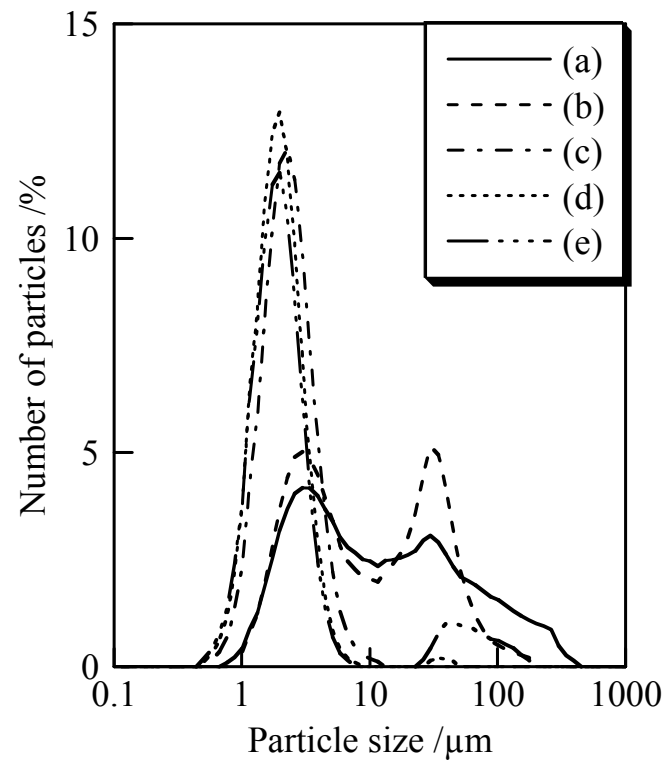

Figure 5. Particle size distribution of samples prepared in hydrothermal treatment for various hours, (a) 0 , (b) 2 , (c) 4 , (d) 8, and (e) 12 hours.

for 2 hours consisted of two normal distributions at 3 and $30 \mu \mathrm{m}$ (Figure 5(b)). On the other hand, samples treated for 4 and 8 hours had a normal distribution at $2 \mu \mathrm{m}$ (Figures 5(c) and (d)). The large particles at $40 \mu \mathrm{m}$ appeared in particle size distribution of sample treated for 12 hours (Figure 5(e)). By heating, the particle size became larger than $10 \mu \mathrm{m}$ (not shown).

For cosmetic application, small and homogenized particles are suitable. However, too much smaller particles had trouble to get into the pores in the skin [3]. The standard size of the white pigment for cosmetics is difficult to determine, because the size of pore in the skin is determined from age, gender, climate, and so on. Further, too much larger particles are also inappropriate because of the cracking of coating on the skin. It is important to control the particle size of pigments. The hydrothermal treatment has the possibility to control the particle size of titanium phosphate pigments for the cosmetics.

\subsection{Cosmetic Properties of Titanium Phosphates}

Figure 6 shows the photo catalytic activity of samples prepared in various conditions. When samples had the photo catalytic activity, the residual ratio of methylene blue became lower. This residual ratio was calculated from the adsorption at $660 \mathrm{~nm}$. Because titanium dioxide is used as a white pigment in cosmetics, this compound was evaluated for the comparison with uncoated titanium phosphate [1]. The methylene blue was decomposed with titanium dioxide by UV radiation (Figure 6(e)). On the other hand, titanium phosphate had little photo catalytic

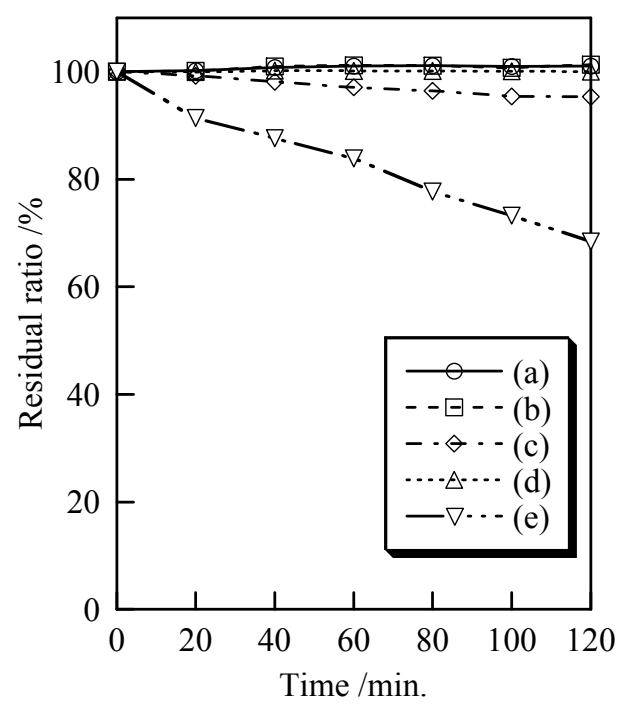

Figure 6. Photo catalytic activity of samples prepared in hydrothermal treatment for various hours and then heated, (a) blank, (b) 0 hour, R.T., (c) 8 hours, R.T., (d) 8 hours, $400{ }^{\circ} \mathrm{C}$, and (e) $\mathrm{TiO}_{2}$.

activity in spite of the hydrothermal time and heating temperature (Figures 6(b)-(d)). Titanium phosphate was mild material to protect the sebum on the skin.

Figure 7 shows UV-Vis reflectance spectra of samples prepared in hydrothermal treatment for various hours. All samples and titanium oxide indicated high reflectance at the range of visible light. Titanium oxide adsorbed the ultraviolet light that was shorter than $400 \mathrm{~nm}$ in wavelength. On the other hand, samples prepared in the hydrothermal treatment for 4,8 , and 12 hours absorbed the light shorter than $360 \mathrm{~nm}$ in wavelength.

As mentioned above, the pigment with high smoothness spreads well on the skin. The smoothness of the powders is also important in cosmetics [18]. Table 1 shows the smoothness of samples prepared in hydrothermal process for several hours. The values of MIU and MMD represented the slipping resistance and roughness of powders, respectively. Sample powders spread on the article leather, and then a sensor ran on these powders. The values of MIU and MMD were calculated from the power to move a sensor and the pitching of a sensor, respectively. The value of MIU became small with the hydrothermal treatment. Samples had less change in the value of MMD by the hydrothermal treatment. Table 2 shows the smoothness of samples heated at several temperatures. By heating, the value of MIU became larger, because the heated samples had large and dispersed particles in size. The value of MMD was less affected from the heating temperatures. As a pigment for cosmetics, the heated phosphates were less suitable than sample without heating. 


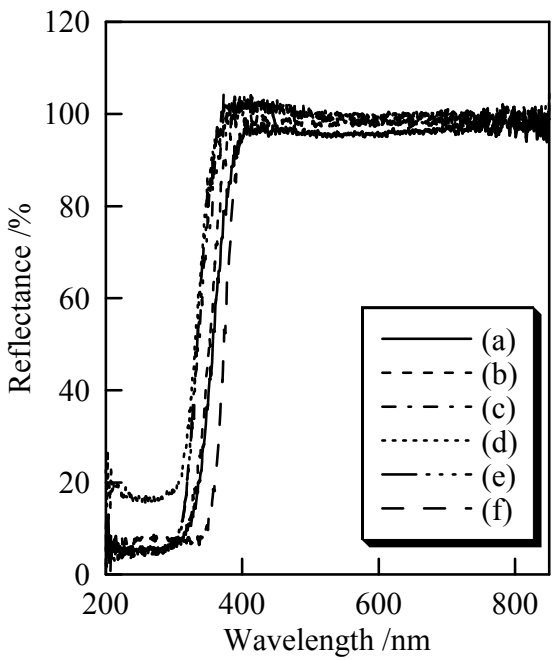

Figure 7. UV-Vis reflectance spectra of samples prepared in hydrothermal treatment for various hours, (a) 0 , (b) 2 , (c) 4 , (d) 8, (e) 12 hours, and (f) $\mathrm{TiO}_{2}$.

Table 1. Smoothness of samples prepared for various hydrothermal hours.

\begin{tabular}{ccc}
\hline Hydrothermal time/h & MIU & MMD \\
\hline 0 & 0.250 & 0.008 \\
2 & 0.204 & 0.006 \\
4 & 0.201 & 0.006 \\
8 & 0.193 & 0.006 \\
12 & 0.231 & 0.006 \\
\hline
\end{tabular}

Table 2. Smoothness of samples (hydrothermal time; 8 hours) heated at several temperatures.

\begin{tabular}{ccc}
\hline Temperature $/{ }^{\circ} \mathrm{C}$ & MIU & MMD \\
\hline R.T. & 0.193 & 0.006 \\
100 & 0.224 & 0.007 \\
200 & 0.263 & 0.007 \\
400 & 0.258 & 0.008 \\
600 & 0.231 & 0.006 \\
\hline
\end{tabular}

\section{Conclusion}

Titanium phosphates were obtained from titanium chloride and sodium triphosphate solution. The obtained materials had a certain degree of amorphous phase. These titanium phosphates had less photo catalytic activity to protect the sebum on the skin. The particle size of phosphate pigments consisted of a normal distribution at 2 $\mu \mathrm{m}$ by the hydrothermal treatment for 4 and 8 hours. The slipping resistance of sample powders became small by the hydrothermal treatment.

\section{Acknowledgements}

The authors gratefully thank Dr. Takeshi Toyama, Nihon University, Japan, for the measurements of the smoothness.

\section{REFERENCES}

[1] U. Diebold, "The Surface Science of Titanium Dioxide," Surface Science Report, Vol. 48, No. 5-8, 2003, pp. 53229. doi:10.1016/S0167-5729(02)00100-0

[2] M. Senzuki, T. Tamura, K. Miura, Y. Ikarashi, Y. Watanabe and M. Fujii, "Study on Penetration of Titanium Dioxide $\left(\mathrm{TiO}_{2}\right)$ Nanoparticles into Intact and Damaged Skin in Vitro," The Journal of Toxicological Sciences, Vol. 35, No. 1, 2010, pp. 107-113. doi:10.2131/jts.35.107

[3] A. O. Gamer, E. Leibold and B. Van Ravenzwaay, "The in Vitro Absorption of Microfine Zinc Oxide and Titanium Dioxide through Porcine Skin," Toxicology in Vitro, Vol. 20, No. 3, 2006, pp. 301-307. doi:10.1016/i.tiv.2005.08.008

[4] H. Onoda, H. Nariai, A. Moriwaki, H. Maki and I. Motooka, "Formation and Catalytic Characterization of Various Rare Earth Phosphates," Journal of Materials Chemistry, Vol. 12, No. 6, 2002, pp. 1754-1760. doi:10.1039/b110121h

[5] H. Onoda, T. Ohta, J. Tamaki and K. Kojima, "Decomposition of Trifluoromethane over Nickel Pyrophosphate Catalysts Containing Metal Cation," Applied Catalysis A; General, Vol. 288, No. 1-2, 2005, pp. 98-103. doi:10.1016/j.apcata.2005.04.028

[6] D. J. Jones, G. Aptel, M. Brandhorst, M. Jacquin, J. Jimenez-Jimenez, A. Jimenez-Lopez, P. Maireles-Torres, I. Piwonski, E. Rodrigues-Castellon, J. Zajac and J. Roziere, "High Surface Area Mesoporous Titanium Phosphate: Synthesis and Surface Acidity Determination," Journal of Materials Chemistry, Vol. 10, No. 8, 2000, pp. 1957-1963. doi:10.1039/b002474k

[7] H. Onoda, H. Matsui and I. Tanaka, "Improvement of Acid and Base Resistance of Nickel Phosphate Pigment by the Addition of Lanthanum Cation," Materials Science and Engineering B, Vol. 141, No. 1-2, 2007, pp. 28-33. doi:10.1016/j.mseb.2007.05.009

[8] A. Bhamik and S. Inagaki, "Mesoporous Titanium Phosphate Molecular Sieves with Ion-Exchange Capacity," Journal of American Chemical Society, Vol. 123, No. 4, 2001, pp. 691-696. doi:10.1021/ja002481s

[9] C. Xu, J. Lee and A. S. Teja, "Continuous Hydrothermal Synthesis of Lithium Iron Phosphate Particles in Subcritical and Supercritical Water," Journal of Supercritical Fluids, Vol. 44, No. 1, 2008, pp. 92-97. doi:10.1016/j.supflu.2007.09.001

[10] R. Vani, E. K. Girija, K. Elayaraja, S. P. Parthiban, R. Kesavamoorthy and S. N. Kalkura, "Hydrotehrmal Synthesis of Porous Triphasic Hydroxyapatite/(Alpha and Beta) Tricalcium Phosphate," Journal of Materials Science: Materials in Medicine, Vol. 20, Suppl. 1, 2009, pp. 43-48. doi:10.1007/s10856-008-3480-8

[11] M. Tomozawa and S. Hiromoto, "Microstructure of Hy- 
droxyapatite- and Octacalcium Phosphate-Coatings Formed on Magnesium by a Hydrothermal Treatment at Various pH Values," Acta Materialia, Vol. 59, No. 1, 2011, pp. 355-363. doi:10.1016/i.actamat.2010.09.041

[12] H. Onoda and T. Yamaguchi, "Preparation of Titanium Phosphate with Additives and Powder Properties for Cosmetics," Materials Science and Applications, Vol. 3, No. 1, 2012, pp. 18-23. doi:10.4236/msa.2012.31003

[13] V. Ramaswamy, N. B. Jagtap, S. Vijayanand, D. S. Bhange and P. S. Awati, "Photocatalytic Decomposition of Methylene Blue on Nanocrystalline Titania Prepared by Different Methods," Materials Research Bulletin, Vol. 43, No. 5, 2008, pp. 1145-1152.

doi:10.1016/j.materresbull.2007.06.003

[14] P. Du, A. Bueno-Lopez, M. Verbaas, A. R. Almeida, M. Makkee, J. A. Moulijn and G. Mui, "The Effect of Surface OH-Population on the Photocatalytic Activity of Rare Earth-Doped $\mathrm{P} 25-\mathrm{TiO}_{2}$ in Methylene Blue Degrada- tion," Journal of Catalysis, Vol. 260, No. 1, 2008, pp. 75-80. doi:10.1016/j.jcat.2008.09.005

[15] W. T. A. Harrison, T. E. Gier and G. D. Stucky, "Titanium (III) Tris(metaphosphate)," Acta Crystallographica, Section C, Vol. 50, No. 11, 1994, pp. 1643-1646. doi:10.1107/S010827019400613X

[16] H. Maeda, M. Matsushita, M. Tsuhako, H. Nariai and H. Nakayama, "Phosphorylation of Polyamidoamine Dendrimers with Cyclo-Triphosphate in Aqueous Solution," Phosphorus Research Bulletin, Vol. 23, 2009, pp. 52-56. doi: $10.3363 /$ prb.23.52

[17] M. T. Averbuch and A. Durif, "Topics in Phosphate Chemistry," World Scientific Publishing, Singapore, 1996.

[18] S. Y. Cheng, C. W. M. Yuen, C. W. Kan, K. K. L. Cheuk, J. C. O. Tang and S. Y. Li, "A Comprehensive Study of Silicone-Based Cosmetic Textile Agent," Fibers and Polymers, Vol. 10, No. 1, 2009, pp. 132-140. 